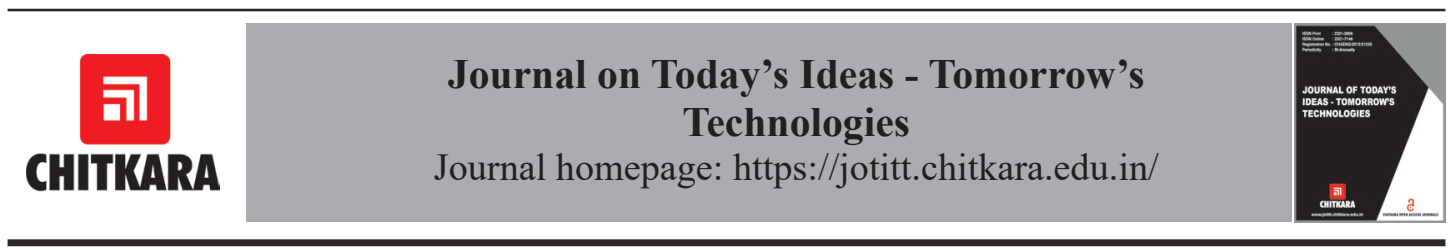

\title{
Automatic Door Handle or Knob Sanitizer
}

\author{
Sundram Singh* and Aditya Garg \\ Chitkara University Institute of Engineering \& Technology, Chitkara University, Punjab-140401, India
}

Email: ssingh2105.ece18@chitkara.edu.in*

\section{ARTICLE INFORMATION}

Received: June 15, 2020

Revised: June 20, 2020

Accepted: June 24, 2020

Published online: December 03, 2020

Keywords:

COVID-19, Automatic sanitizer, Door knob sanitizer, Arduino-nano, IR sensor

\begin{abstract}
An increase in the risk of COVID-19 spread led people, industries and the government to adopt various approaches for controlling the transmission rate of COVID-19 viruses. Although each approach has its advantages, but in terms of cost-effectiveness and flexibility, one approach i.e. Arduino based sanitizing systems have played an important role to prevent the coronavirus from spreading. In the direction of this research field, a lot of researchers have exerted great efforts to control the COVID-19 outbreak. However, an automatic door handle and knob sanitizer based on IR sensor and servo motor has not been reported till date as per our knowledge. Therefore, In this paper, we have demonstrated an automatic door handle sanitizer to sanitize the handle or knob of a door that is generally used by many people in houses, hospitals, and industries, etc. The reported work has been done to prevent people from getting infected by the coronavirus. If anyone gets infected by touching the contaminated door knob of any institution, house, hospital, etc., then it will have a severe effect on the person as well as on his country. In this regard, the reported system sanitizes the door handle to remove the virus from it as the person touches the door knob. The demonstrated system contains Arduino-Nano, Servo motor, Bread-board and an IR Sensor. It can be implemented in public places such as hospitals, companies where the doors are used frequently to break the chain of COVID-19 infection.
\end{abstract}

DOI: $10.15415 /$ jotitt.2020.81006

\section{Introduction}

The advancement goes back to December 2019 when the novel coronavirus disease (COVID-19) was identified in Wuhan, Hubei Province, China due to severe acute respiratory syndrome corona virus 2 (SARS-CoV-2)" [1]. The people across the world started getting infected with corona virus and in almost half the year the death rate due to COVID-19 is approx. 6 million and the rate of affected people is over 12 million. This disease is usually transmitted through the cough, sneeze, inhalation, and contaminated surface as small droplets can be suspended in the air as aerosols [2]. Various researchers have reported in their work [3-6] that hands are the critical route to transmit viruses. Therefore, hand washing is widely considered to be the 
most important preventive measure during the COVID-19 pandemic [4].

Furthermore, proper hand hygiene is the most important safety tool to stop the transmission of the COVID-19 infection in public healthcare institutions such as hospitals and nursing homes. One can understand the need to break the chain of COVID-19 infection from the following example. Let us assume a lady sitting behind her husband who was under treatment for corona virus in a hospital. If she touches her husband then her hands get infected and at that time she touches the door handle to open for going outside the patient room. Therefore, in this way the virus gets attached to the handle. Further, if the hospital compounder touches the same handle, he also gets infected and when he delivers the file to the nurse then she also gets infected. The aforementioned example can lead us to understand that many people get infected from the only one person and they even don't know about it.

Many Arduino-based projects have been made to break the chain of COVID-19 infection [7-9]. Some of the projects are based on the system of closing the door i.e. when the doors close, the sanitizer sanitizes the door handle or knob but in any case, if the door didn't get close then there would be a risk of spreading the virus. This limitation can be overcome by the given project explained in [3]. However, the engineers have not used Infrared Sensor (IR) to detect the person's hand. Further, to improve the sanitizing based projects, we have designed an automatic door handle or knob sanitizer in which the reported product sanitizes the door handle or knob when a person touches the doorknob or handle.

The reported project may be used in public areas i.e. hospitals, schools, private companies, colleges etc. to stop the infection. The present work has been structured into three sections. Section II provides a detailed methodology of the reported project i.e. Automatic Door Handle or Knob Sanitizer. The important results of the designed product have been discussed in section III. The conclusion of the present paper is drawn in the last section.

\section{Methodology}

In this section, the methodology has been elaborated to design the automatic door handle or knob sanitizer. Fig. 1 shows the design methodology and Fig. 2 shows the circuit diagram of the automatic door handle or knob sanitizer.

As shown in Fig. 1, the main controlling unit is a microcontroller i.e. Arduino Nano that behaves as the central unit for the whole system. It has been observed from Fig. 2 that the sensor chip at the input end is connected with the Arduino nano through its interfaces for gathering current readings. At the output-side of the reported product, the interfaces of the aforementioned microcontroller are connected with the servo motor to spray the sanitizer. The microcontroller is also connected to sensor to retrieve information and send data to the servo motor to further rotate in the required direction.
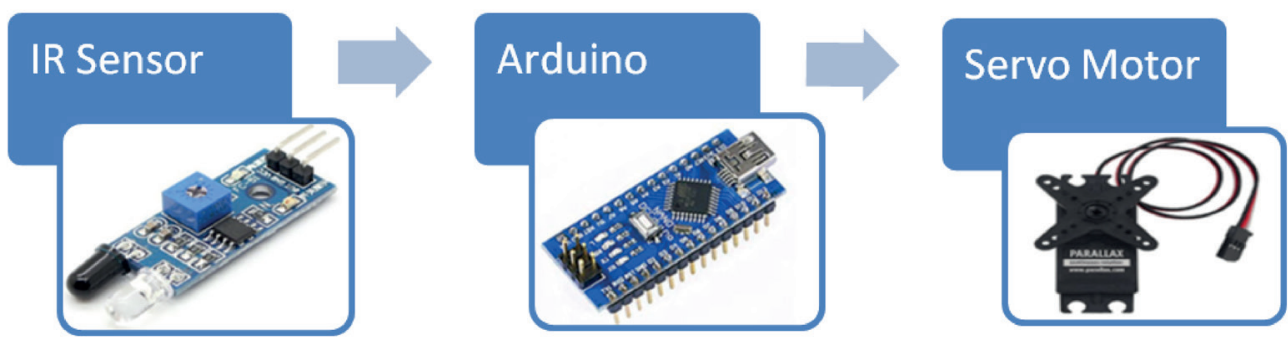

Figure 1: Design methodology of an automatic door handle/knob sanitizer 


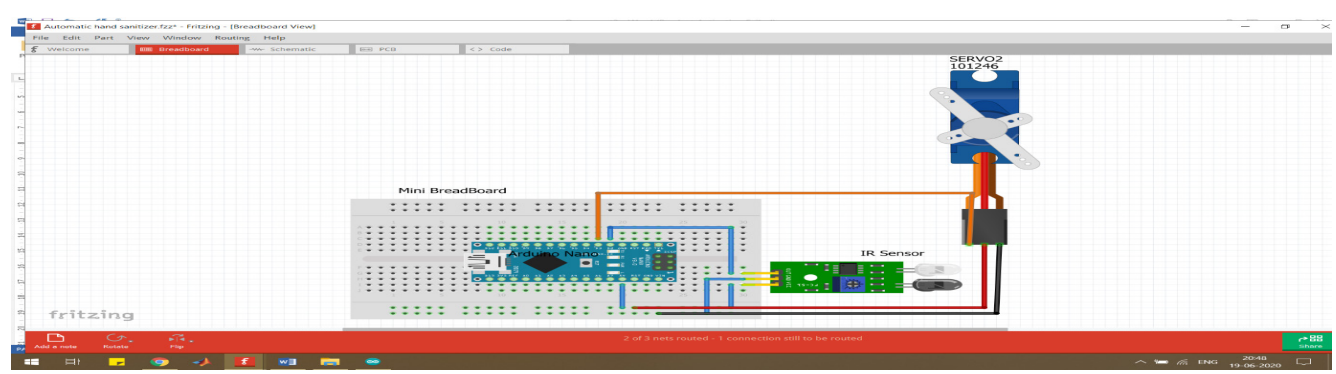

Figure 2: Circuit diagram of an automatic door handle or knob sanitizer

\subsection{Used Components}

\subsubsection{Infrared (IR) Sensor}

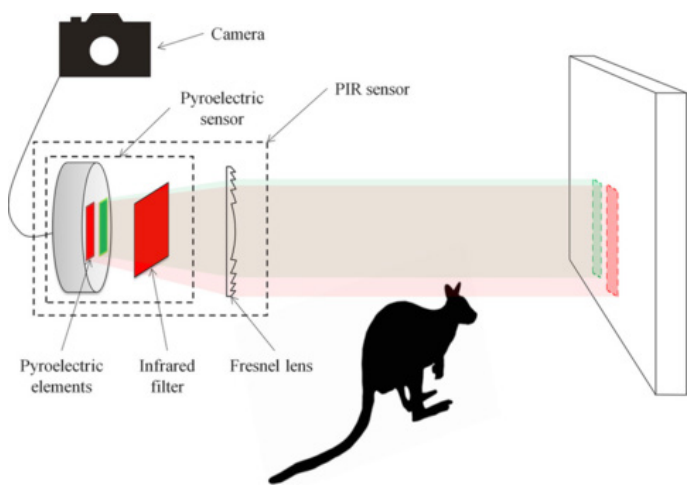

Figure 3: Working of IR sensor

An infrared (IR) sensor is an electronic device that measures and detects infrared radiation in its surrounding environment. Anything that emits heat (everything that has a temperature above around five degrees Kelvin) gives off infrared radiation. There are two types of infrared sensors: active and passive. Active infrared sensors both emit and detect infrared radiation. Active IR sensors have two parts: a light-emitting diode (LED) and a receiver. When an object comes close to the sensor, the infrared light from the LED reflects off of the object and is detected by the receiver as depicted in Fig. 3. Active IR sensors act as proximity sensors and they are commonly used in obstacle detection systems (such as in robots). The $\mathrm{Vcc}(5 \mathrm{~V})$ pin of the IR sensor connects to the $5 \mathrm{~V}$ pin of the Arduino GND pin of the IR sensor which connected to the ground (GND) pin of Arduino. In the next step, the Out pin of the IR sensor is connected to Pin 2 (D2 pin of Arduino).

\subsubsection{Servo Motor}

A servo motor is a rotary actuator or a motor that allows for precise control in terms of the angular position, acceleration, and velocity. Basically, it has certain capabilities that a regular motor does not have. Consequently, it makes use of a regular motor and pairs it with a sensor for position feedback. Servo motors can be of different types based on their applications. AC servo motor, DC servo motor, brushless DC servo motor, positional rotation servo motor are the most useful motors amongst them (See Fig. 4 ), continuous rotation servo motor and linear servo motor. The Brown wire/ground wire of the servo motor is connected to GND pin of Arduino, Red wire is connected to Vcc (5V), and the Orange wire/Out wire is connected to Pin3 (D3 pin of Arduino).

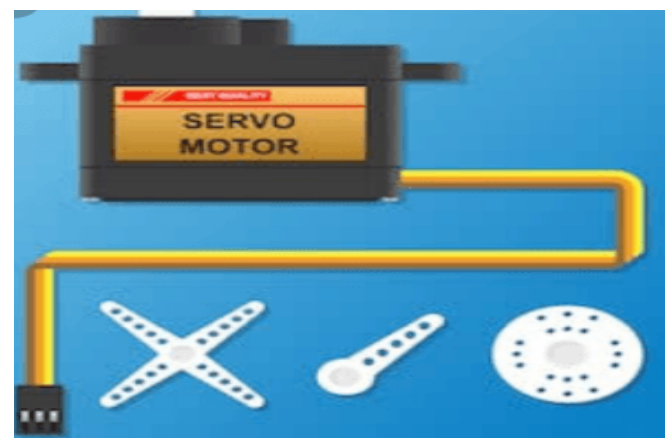

Figure 4: Positional rotation servo motor 


\subsubsection{Arduino Nano}

Arduino Nano is a small, compatible, flexible, and breadboard-friendly Microcontroller board, developed by Arduino.cc in Italy, based on ATmega328p (Arduino Nano V3.x) / Atmega 168 ( Arduino Nano V3.x). It comes with the same functionality as in Arduino UNO but quite a small size. The specifications for the used Arduino Nano have been provided in Table 1 .

Table 1: Specifications of an Arduino component

\begin{tabular}{|l|l|}
\hline Microcontroller & Atmega328p/Atmega 168 \\
\hline Operating Voltage & $5 \mathrm{~V}$ \\
\hline Input Voltage & $7-12 \mathrm{~V}$ \\
\hline Digital I/O Pins & 14 \\
\hline PWM & 6 out of 14 digital pins \\
\hline Max. Current Rating & $40 \mathrm{~mA}$ \\
\hline USB & Mini \\
\hline Analog Pins & 8 \\
\hline Flash Memory & $16 \mathrm{~KB}$ or $32 \mathrm{~KB}$ \\
\hline SRAM & $1 \mathrm{~KB}$ or $2 \mathrm{~KB}$ \\
\hline Crystal Oscillator & $16 \mathrm{MHz}$ \\
\hline
\end{tabular}

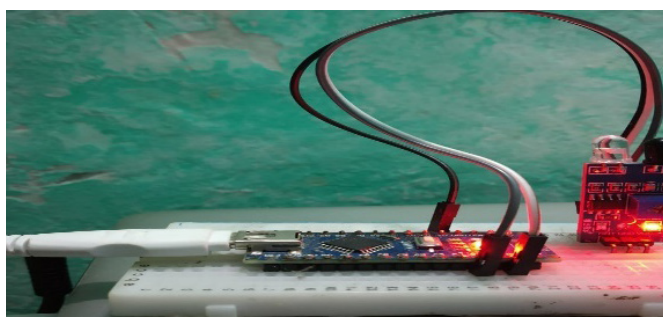

(a)

\begin{tabular}{|l|l|}
\hline EEPROM & 512 bytes or $1 \mathrm{KN}$ \\
\hline USART & Yes \\
\hline
\end{tabular}

Source: www.theengineeringprojects.com

\subsection{Working}

The working of the reported project has been demonstrated in Fig. 5 and Fig. 6. It has been observed from these figures that the authors have used an active IR sensor in such a way that when a person touches the doorknob or handle by hand then it reflects the light and the IR sensor receives the signal i.e., the value of IR sensor changes from 0 to 1 , and if the person removes his hand, IR Sensor sends the value to Arduino Nano as 1 and after receiving the value as 1 , Nano sends the signal to the servo to rotate 180 degrees. After this step, servo receives the command and rotates 180 degrees and pull back the sprayer handle of the bottle backward and bottle spray the sanitizer in the handle after that servo came back to its o degrees and wait for the next person to touch the handle.

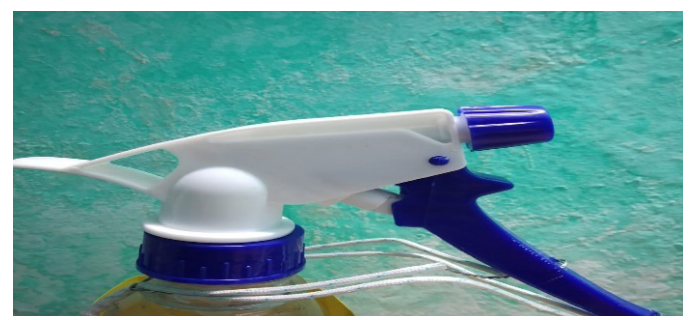

(b)

Figure 5: (a) The status of the reported project and (b) the position of the sanitizer bottle pump before a person touches the door handle or knob.

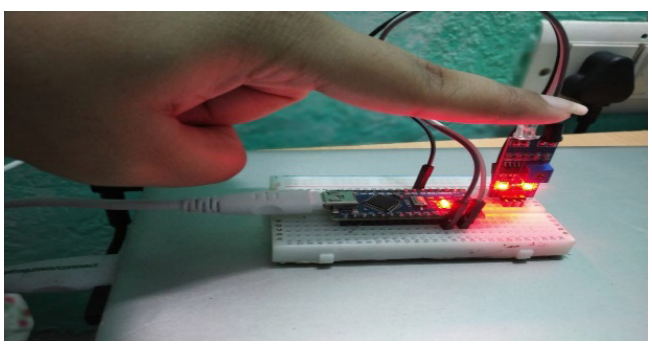

(a)

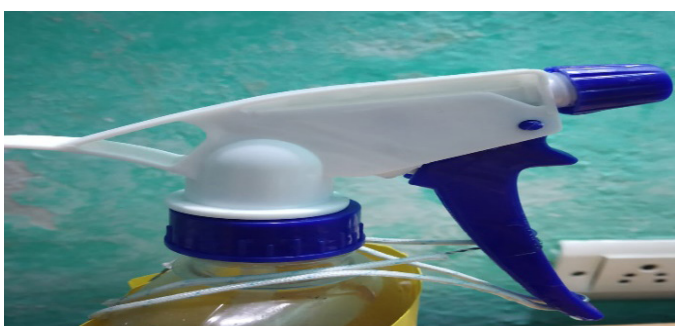

(b)

Figure 6: (a) The status of the reported project and working of IR sensor/Arduino Nano, and (b) the position of the sanitizer bottle pump when the person touches the door handle or knob 


\section{Results and Discussion}

The reported project shown in Fig. 7 may be implemented in those areas where there is a huge crowd and chances of infection are quite. Therefore, it can be used in educational institutions, houses, hospitals, and offices, etc. to stop the spread of corona virus. This product is different from the available products in the market as it is based on sensing and rotating method i.e. when the IR sensor senses the hand, the servo rotates and pull the handle of sanitizer towards it rather than earlier reported project [9] i.e., it pushes the spring downwards. Through this project, a person can learn how IR sensors, servo motors work if they want to make it at their home and this is quite cost-effective. Figure 7 shows the prototype of the reported product. When an infected person touches the door, then the virus gets attached to the doorknob. At that time, this product will help to sanitize the door handle.

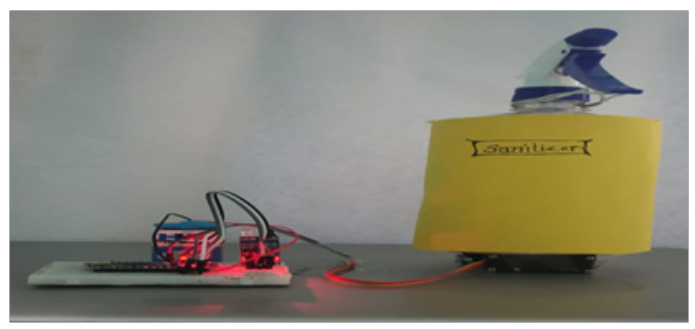

Figure 7: Prototype of product

\section{Conclusion}

At present, the world is facing a difficult time of corona virus pandemic because there is no vaccine to prevent till date. Hence, every positive step taken in this direction is very important. In the direction of the research field to find out the preventive measure, we have demonstrated an automatic door handle sanitizer based on Arduino Nano, IR sensor, and servo motor to sanitize the handle or knob of the door that is used by many people. As a result of this, the handle or knob of the door can be sanitized automatically whenever the person touches it. The reported project would be a very helpful project for India as well as different countries to protect their families, friends, Citizens to stop the spread of the virus through door gates. Owing to the extensive use of the door handle by users at public places, there is a higher probability of transmission of COVID-19 virus. Therefore, the reported Project/System may help to reduce the risk of spreading the COVID-19 virus.

\section{References}

[1] World Health Organization. Naming the coronavirus disease (COVID-19) and the virus that causes it. ed, 2020.

[2] L. Morawska, J. W. Tang, W. Bahnfleth, P. M. Bluyssen, A. Boerstra, G. Buonanno, et al. How can airborne transmission of COVID-19 indoors be minimised?. Environment international, vol. 142, p. 105832, 2020. https://doi.org/10.1016/j. envint.2020.105832

[3] M. Alzyood, D. Jackson, H. Aveyard, and J. Brooke. COVID-19 reinforces the importance of hand washing. Journal of Clinical Nursing, 2020. https://doi. org/10.1111/jocn.15313

[4] M. Alzyood, D. Jackson, J. Brooke, and H. Aveyard. An integrative review exploring the perceptions of patients and healthcare professionals towards patient involvement in promoting hand hygiene compliance in the hospital setting. Journal of clinical nursing, vol. 27, pp. 1329-1345, 2018. https://doi.org/10.1111/jocn.14305

[5] B. Allegranzi, L. Conway, E. Larson, and D. Pittet. Status of the implementation of the World Health Organization multimodal hand hygiene strategy in United States of America health care facilities. American journal of Infection Control, vol. 42, pp. 224-230, 2014. https://doi.org/10.1016/j. ajic.2013.11.015

[6] D. S. C. Lam, R. L. M. Wong, K. H. W. Lai, C.-N. Ko, H. Y. Leung, V. Y. W. Lee, et al. COVID-19: special precautions in ophthalmic practice and FAQs on personal 
Sundram Singh and Aditya Garg, J. Today's Ideas - Tomorrow's Technology, Vol. 8, No. 1 (2020) pp. 35-40

protection and mask selection. Asia-Pacific Journal of Ophthalmology (Philadelphia, Pa.), 2020. https://doi.org/10.1097/AP O.0000000000000280

[7] University Hospitals Birmingham NHS Foundation Trust. Infection control: break the chain. 2010. [online] Available: https:// youtu.be/_o9SxDFPUiA [Accessed: June 2020)
[8] Bunzl Cleaning \& Hygiene Supplies. Handle Hygiene Door Handle Sanitiser. 2017. [Online) Available: https://youtu.be/ DBvWoqII6hY [Accessed: June 2020).

[9] Aatik's lab. DIY Door Handle Sanitizer || Corona Virus Precaution. 2020. [Online] Available: https://youtu.be/DPo6k6w2ILE [Accessed: June 2020).

This article has been published as a part of Special regular issue of Journal on Today's Ideas Tomorrow's Technologies. Most of the articles in this issue are the papers for which the original ideas were presented at NOVATE 2020 (https://www.chitkara.edu.in/novate), a competition organized by Chitkara University and supported by Ministry of Electronics and Information Technology, Govt. Of India, Institution's Innovation Council, NSTEDB, Govt. Of India and FICCI. Student participants have written most of these articles. Some basic editing work has been done at the editorial level, but same have not been corrected very rigorously so as to preserve basic touch of student's writing.
旬
CHITKARA
Journal on Today's Ideas - Tomorrow's Technologies
Chitkara University, Saraswati Kendra, SCO 160-161, Sector 9-C, Chandigarh, 160009, India

Volume -8, Issue-1

June 2020

ISSN 2321-3906

Copyright: [ $($ C 2020 Sundram Singh and Aditya Garg] This is an Open Access article published in Journal on Today's Ideas - Tomorrow's Technologies by Chitkara University Publications. It is published with a Creative Commons Attribution- CC-BY 4.0 International License. This license permits unrestricted use, distribution, and reproduction in any medium, provided the original author and source are credited. 